\title{
Use of tiotropium Respimat Soft Mist Inhaler versus HandiHaler and mortality in patients with COPD
}

\author{
Katia M.C. Verhamme ${ }^{1,4}$, Ana Afonso ${ }^{1,4}$, Silvana Romio ${ }^{1}$, Bruno C. Stricker ${ }^{2}$, \\ Guy G.O. Brusselle ${ }^{2,3}$ and Miriam C.J.M. Sturkenboom ${ }^{1,2}$
}

Affiliations: ${ }^{1}$ Dept of Medical Informatics, Erasmus University Medical Center, Rotterdam, and ${ }^{2}$ Dept of Epidemiology, Erasmus University Medical Center, Rotterdam, The Netherlands. ${ }^{3}$ Dept of Respiratory Medicine, Ghent University Hospital, Ghent, Belgium. ${ }^{4}$ Both authors contributed equally to this work.

Correspondence: K.M.C. Verhamme, Dept of Medical Informatics, Erasmus MC, PO Box 2040, 3000 CA Rotterdam, the Netherlands. E-mail: k.verhammederasmusmc.nl

ABSTRACT Tiotropium, a long-acting anticholinergic, is delivered via HandiHaler or via Respimat. Randomised controlled trials suggest that use of tiotropium Respimat increases the risk of dying. We compared the risk of mortality between tiotropium Respimat versus HandiHaler.

Within the Integrated Primary Care Information database, we defined a source population of patients, aged $\geqslant 40$ years, with $\geqslant 1$ year of follow-up. Based on prescription data, we defined episodes of tiotropium use (Respimat or HandiHaler). The risk of mortality, within these episodes, was calculated using a Cox proportional hazard regression analysis.

From the source population, 11287 patients provided 24522 episodes of tiotropium use. 496 patients died while being exposed to HandiHaler or Respimat. Use of Respimat was associated with almost $30 \%$ increased risk of dying (adjusted HR 1.27, 95\% CI 1.03-1.57) with the highest risk for cardiovascular/ cerebrovascular death (adjusted HR 1.56, 95\% CI 1.08-2.25). The risk was higher in patients with coexisting cardiovascular disease (adjusted HR 1.36, 95\% CI 1.07-1.73) than in patients without (adjusted HR $1.02,95 \%$ CI $0.61-1.71$ ).

Use of tiotropium Respimat was associated with an almost 30\% increase of mortality compared with HandiHaler and the association was the strongest for cardiovascular/cerebrovascular death. It is unclear whether this association is causal or due to residual confounding by chronic obstructive pulmonary disease severity.

@ERSpublications

Tiotropium Respimat was associated with a $30 \%$ increase in mortality compared with HandiHaler in COPD http://ow.ly/mpmhp

For editorial comments see pages 584 and 590 .

Received: Jan 112013 | Accepted: March 072013 | First published online: March 212013

Conflict of interest: Disclosures can be found alongside the online version of this article at www.erj.ersjournals.com 


\section{Introduction}

Chronic obstructive pulmonary disease (COPD) is a leading cause of death worldwide, and it is known that the rate of COPD-related death is increasing [1]. COPD is characterised by a progressive decline in lung function which cannot be reversed by treatment. Bronchodilators are the mainstay of symptomatic management of COPD and include $\beta_{2}$ agonists, anticholinergics and methylxanthines, used alone or in combination [2]. Long-acting bronchodilators are more effective and convenient than the short-acting agents at producing maintained symptom relief [2]. Tiotropium is a long-acting inhaled anticholinergic bronchodilator developed for the long-term, once daily, maintenance treatment of COPD. The efficacy and safety of tiotropium have been demonstrated in randomised controlled trials, with a significantly lower risk of COPD exacerbations and statistically non-significant reductions for mortality [3]. Tiotropium is delivered either by the HandiHaler device, a single-dose dry powder inhaler (DPI) or via Respimat Soft Mist Inhaler (SMI), a novel propellant-free inhaler.

Tiotropium HandiHaler (Spiriva) is a potent long-acting bronchodilator for which clinical benefits have been established in several clinical studies [3-6]. The lung function improvements and the safety associated with tiotropium HandiHaler have been reported in clinical trials of COPD patients [5, 7-11], including the UPLIFT (Understanding Potential Long-term Impacts on Function with Tiotropium) study which is the largest long-term randomised controlled trial studying the efficacy and safety of tiotropium HandiHaler conducted so far.

Tiotropium Respimat SMI has been developed and proposed as an alternative device [12]. Based on its lower velocity, Respimat SMI improves lung drug deposition, reduces oropharyngeal deposition and may require a lower dose of drug than normally used with either dry powder inhalers or metered-dose inhalers $[13,14]$.

In 2008, concerns were raised on the cardiovascular and cerebrovascular safety of tiotropium HandiHaler. These concerns were based on 1) a report to the US Food and Drug Administration (FDA), issued by Boehringer Ingelheim, the manufacturer of Spiriva, on pooled data from 29 placebo-controlled trials showing an increased risk of stroke in patients treated with tiotropium; and 2) a meta-analysis and a casecontrol study reporting an increased risk of mortality and/or cardiovascular events in patients who received inhaled anticholinergics (ipratropium or tiotropium) [15-17]. In their initial report to the US FDA, Boehringer Ingelheim also reported an increased risk of mortality with tiotropium Respimat SMI device based on data from three 1-year placebo-controlled trials. In January 2010, the US FDA warning on the use of tiotropium HandiHaler was overruled, based on data from the UPLIFT study and updated meta-analysis (including the UPLIFT study), stating that the available data no longer supported an association between the use of tiotropium HandiHaler and an increased risk of stroke, heart attack or death from cardiovascular causes. [17] However, the concerns on the safety of tiotropium Respimat remained and SINGH et al. [18] published a meta-analysis in 2011 based on data from five randomised controlled trials showing a 50\% increased risk of mortality of tiotropium Respimat SMI compared with placebo. Since the publication of the meta-analysis by SINGH et al [18] in 2011, new data were reported by DoNG et al. [19]. These researchers conducted a meta-analysis to compare the safety of inhaled drugs (inhaled corticosteroids, long-acting $\beta$ agonists and long-acting muscarinic antagonists) in patients with COPD via mixed treatment comparison. They included 42 trials with 52516 subjects enrolled, and reported an increased risk of mortality (OR 1.65, 95\% CI 1.13-2.43) in patients treated with tiotropium Respimat SMI versus tiotropium HandiHaler [19].

The current available data do not allow drawing of strong conclusions on the risk of mortality in patients treated with tiotropium Respimat compared with tiotropium HandiHaler as no direct head-to-head comparisons have been done so far. Therefore, we conducted an observational cohort study to compare the risk of mortality in patients treated with tiotropium Respimat using tiotropium HandiHaler as reference category.

\section{Material and methods \\ Setting}

The study was conducted in the Integrated Primary Care Information (IPCI) Project database. IPCI is a population-based longitudinal observational database that contains the complete computer-based medical records of more than 400 general practitioners (GPs) throughout the Netherlands, who voluntarily chose to supply data to the database [20]. In the Dutch healthcare system, patients are registered with a single GP who acts as a gatekeeper of medical care and information from primary care visits, hospital admission and outpatient visits. At present, the ICPI database contains information on more than one million active patients. The IPCI database contains anonymised patient identification information (age, sex, patient identification number and GP registration information), narratives, symptoms, signs, GP and specialist diagnoses, prescriptions, physical findings, laboratory values and summaries of specialist letters. The 
International Classification of Primary Care (ICPC) is the coding system for patient complaints and diagnoses but they can also be entered as free text [21]. Therefore, the medical records do not only capture GP diagnoses and symptoms, but also the results and summaries of specialist care. Prescription data encompass product name, quantity dispensed, dosage regimens, formulation, strength and indication. The National Database of Drugs, maintained by the Royal Dutch Association for the Advancement of Pharmacy, enables the coding of prescriptions, according to the Anatomical Therapeutic Chemical (ATC) classification scheme recommended by the World Health Organization. IPCI complies with European Union guidelines on the secondary use of healthcare data for medical research and has been proven valid for pharmacoepidemiological research [22]. Guidelines on good pharmaco-epidemiological research are rigorously followed by all researchers working on the IPCI database [23].

\section{Source population}

The source population consisted of all patients registered in the IPCI database, aged $\geqslant=40$ years and with $\geqslant 1$ year of valid database history. This meant that the practice had been contributing data to the IPCI database for at $\geqslant 1$ year and that the patient had been registered with the GP for $\geqslant 1$ year. This 1 -year preenrolment period was required to characterise the patients in terms of co-existing co-morbidity. The study period lasted from January 1, 2008 up to June 1, 2011.

\section{Tiotropium cohort}

All patients who received a prescription for tiotropium during follow-up (split in an inception and prevalent user group), were included in the tiotropium cohort. Cohort entry was the date of first prescription (either Respimat SMI or HandiHaler: inception cohort) or start of follow-up for prevalent users. Episodes of use were created based on repeat prescription of the same type.

A patient was considered as being a switcher when switching from Respimat SMI to HandiHaler or vice versa. Subjects were followed from episode start of tiotropium use (either Respimat SMI or HandiHaler) until the stop date of the episode of use (+30 days to account for carry over), the end of follow-up or death, whichever occurred first. Death was assigned to an exposure category if it occurred during use or with a maximum of 30 days after stopping use.

Death

To assess the cause of death, the complete medical file of the patients was reviewed and information on cause of death was retrieved from either the hospital discharge letters (when patients died in the hospital), from the death certificates or from the cause of death as recorded by the GP. Researchers reviewing the information were blinded to drug (device) exposure. The cause of death was classified into respiratory death (excluding lung cancer), cardio- and cerebrovascular death, death related to cancer, other causes or causes unknown. Patients who died of a combination of cardio- and cerebrovascular death and respiratory death were classified into the former. Patients who died due to euthanasia were excluded from the analysis.

\section{Covariates}

As covariates, we considered smoking history, underlying comorbidities (asthma, angina pectoris, ischaemic heart disease, peripheral arterial disease, myocardial infarction, stroke or transient ischaemic attack, heart failure, ventricular arrhythmia, hypertension, dyslipidaemia, cancer, pneumonia, parkinsonism, depression, dementia, diabetes and renal failure) and use of concomitant medications, all assessed at the start date of the episode of tiotropium use. Smoking history was classified as "ever smoking" or "no smoking". Smoking was defined through an extensive search of the patient's electronic medical file including the use of drugs for smoking cessation. Concomitant drug use included central nervous system drugs, drugs affecting the cerebrovascular and cardiovascular system and drugs affecting the respiratory system.

The presence of COPD was considered as a separate covariate in the analysis. A patient was considered to have COPD based on 1) either the presence of ICPC specific codes for COPD namely ICPC_R95 (chronic obstructive pulmonary disease) or ICPC_R91 (chronic bronchitis), or 2) free text searching including "COPD” OR "chronic bronchitis" OR “emphysema”.

As we did not have spirometry data on all patients and as spirometry is not systematically recorded in the IPCI database, COPD severity was based on algorithms validated and successfully used by other research groups [24-26]. COPD severity was assessed at the start date of each treatment episode based on 1) the number of systemic corticosteroids prescriptions, 2) the number of antibiotics for the treatment of lower respiratory tract infections, 3) previous hospitalisations for COPD exacerbations, and 4) the number of GP visits in the one year prior to treatment episode. 5) In addition, we included visits to the respiratory physician in the one year prior to the episode start as a proxy for COPD severity. 


\section{Statistical analysis}

To compare the baseline characteristics of the patients using tiotropium Respimat SMI or HandiHaler, at start of treatment episode, the non-parametric Mann-Whitney U-test was applied for continuous variables, and the Chi-squared test for categorical variables.

Cox proportional hazards regression analyses were conducted to calculate crude (unadjusted) and adjusted hazard ratios (HR) and their 95\% CI for the risk of all-cause death associated with the use of tiotropium Respimat SMI or HandiHaler. The final model was built upon adjustment for smoking, COPD severity (as described), COPD duration (time from first prescription of bronchodilating drug until start of treatment episode), previous use of tiotropium and adjusting on all factors that changed the crude HR by more than $5 \%$.

Sensitivity analyses were conducted by stratifying on cause of death, underlying co-morbidity of cardiovascular disease (arrhythmia, ischaemic heart disease, heart failure, hypertension, peripheral artery disease and stroke), first episode of tiotropium use (either Respimat SMI or HandiHaler) during follow-up and excluding episodes of switching. In addition, we repeated the analysis first by not considering a 30-day carry over and second by extending the episodes up to the next prescription (i.e. no untreated episodes between prescriptions) [27].

Finally, to control for differential prescribing of tiotropium Respimat SMI (channelling bias where patients with more severe COPD or more underlying comorbidity are preferably prescribed Respimat SMI), we repeated the analysis adjusting for the propensity score to be prescribed tiotropium Respimat SMI. First a logistic regression model with all control variables was built to estimate propensity scores to be treated with tiotropium Respimat SMI. Cox models were stratified across 10ths of the propensity score [28]. All statistical analyses were conducted with the statistical software packages SPSS/PC 20.0 (SPSS Inc, Chicago, IL, USA).

\section{Results}

Cohort of tiotropium users

Within the total source population of 409680 patients, we defined a cohort of 11287 tiotropium users. From the prescription records of these patients, 24522 episodes of tiotropium use (either HandiHaler or Respimat SMI) were delineated. The mean \pm SD age of the patients at the start of the first treatment episode was $68.1 \pm 11.6$ years and $51.9 \%$ of patients were male. 6560 out of the 11287 patients $(58.1 \%)$ were already prescribed a treatment with tiotropium (either HandiHaler or Respimat SMI) at cohort entry and were thus considered as prevalent users. Of the incident users of tiotropium, 70\% were prescribed HandiHaler as first treatment and $30 \%$ Respimat SMI. The mean \pm SD duration of tiotropium use was $155 \pm 232$ days per treatment episode.

Baseline characteristics of patients at start of first prescription of either tiotropium HandiHaler or Respimat SMI are described in table 1. COPD severity and cardiovascular co-morbidity (angina pectoris, peripheral artery disease, myocardial infarction, stroke or transient ischaemic attack, heart failure, dyslipidaemia), cancer, diabetes mellitus, renal failure and pneumonia (in the one year prior to episode start), differed significantly between users of tiotropium HandiHaler or tiotropium Respimat SMI (table 1). The use of concomitant medication, such as opioids, systemic corticosteroids, antibiotics, lipid-lowering drugs, antiplatelet drugs, diuretics, angiotensin converting enzyme inhibitors, mucolytics, short-acting anticholinergics and short-acting $\beta$-agonists also differed significantly between persons prescribed tiotropium HandiHaler versus patients being prescribed tiotropium Respimat SMI (table 1). When considering all treatment episodes, similar differences in baseline characteristics between users of tiotropium HandiHaler and tiotropium Respimat SMI were observed (table 2).

\section{All-cause mortality}

During a total tiotropium exposure of 11973 treatment years, 496 patients died. Of the 496 patients who died, $372(75.0 \%)$ were receiving tiotropium HandiHaler while 124 were receiving tiotropium Respimat SMI (25.0\%). The death rate was 60.7 per 1000 person-years during Respimat exposure and 37.6 per 1000 person-years during HandiHaler exposure. In the crude analysis, use of tiotropium Respimat, compared with use of HandiHaler, was associated with a 50\% increased risk of dying (crude HR 1.57, 95\% CI 1.28 1.92) (table 3). This increased risk remained upon adjustment for confounding factors (age, sex, smoking, COPD severity (including visit to the specialist), duration of COPD, previous episodes of tiotropium use and calendar time) (adjusted HR 1.27, 95\% CI 1.03 - 1.58) (table 3). No dose response relationship was observed.

\section{Cause-specific mortality}

Cause of death was cardiovascular or cerebrovascular in 158 patients (31.6\%), respiratory in 95 patients (19.1\%), cancer in 139 patients $(27.6 \%)$, other causes in 51 patients $(10.2 \%)$ or unknown in 53 patients $(10.7 \%)$. 


\section{TABLE 1 Patient characteristics at start of first treatment episode during follow-up}

\begin{tabular}{|c|c|c|}
\hline Characteristics & Tiotropium HandiHaler & Tiotropium Respimat \\
\hline Number of patients $n$ & 9226 & 2827 \\
\hline Age years & $68.09 \pm 11.6$ & $68.15 \pm 11.8$ \\
\hline \multicolumn{3}{|l|}{ Sex } \\
\hline Male & $4776(51.8)$ & $1468(51.9)$ \\
\hline Female & $4450(48.2)$ & $1359(48.1)$ \\
\hline Smoking history & $7132(77.3)$ & $2180(77.1)$ \\
\hline COPD diagnosis & $8459(91.7)$ & $2567(90.8)$ \\
\hline COPD duration years & $5.29 \pm 4.8$ & $5.23 \pm 5.0$ \\
\hline \multicolumn{3}{|l|}{ COPD severity $\mathrm{n}$} \\
\hline Antibiotics in 1 year prior & $0.47 \pm 1.0$ & $0.64 \pm 1.2$ \\
\hline Systemic corticosteroids in 1 year prior & $0.61 \pm 1.5$ & $0.96 \pm 2.2$ \\
\hline GP visits in the 1 year prior & $7.84 \pm 6.5$ & $9.41 \pm 7.7$ \\
\hline Hospitalisation for COPD exacerbation in 1 year prior & $196 \pm 2.1$ & $124 \pm 4.4$ \\
\hline Consultation with respiratory physician in 1 year prior & $2791 \pm 30.3$ & $1285 \pm 45.5$ \\
\hline \multicolumn{3}{|l|}{ Comorbidity (medical history of any of the conditions) } \\
\hline Asthma & $2874(31.1)$ & $872(30.8)$ \\
\hline Angina pectoris & $1218(13.2)$ & $373(13.2)$ \\
\hline Ischaemic heart disease & $725(7.9)$ & $257[9.1)$ \\
\hline Peripheral arterial disease & $1252(13.6)$ & $430(15.2)$ \\
\hline Myocardial infarction & $650(7.0)$ & $245(8.7)$ \\
\hline Stroke or TIA & $1572(15.3)$ & $382(18.5)$ \\
\hline Heart failure & $952(10.3)$ & $357(12.6)$ \\
\hline Arrhythmia & $878(9.5)$ & $294(10.4)$ \\
\hline Hypertension & $3711(40.2)$ & 1195 (42.3) \\
\hline Dyslipidaemia (lipid disorders) & $1560(16.9)$ & $572(20.2)$ \\
\hline Cancer & $1491(16.2)$ & $529(18.7)$ \\
\hline Pneumonia (1 year before) & $650(7.0)$ & $245(8.7)$ \\
\hline Parkinsonism & $79(0.9)$ & $29(1.0)$ \\
\hline Depression & $1201(13.0)$ & $379(13.4)$ \\
\hline Dementia & $155(1.7)$ & $51(1.8)$ \\
\hline Diabetes mellitus & $1630(17.7)$ & $547(19.3)$ \\
\hline Renal failure & $723(7.8)$ & $266(9.4)$ \\
\hline \multicolumn{3}{|l|}{ Use of concomitant medication at start of prescription } \\
\hline \multicolumn{3}{|l|}{ Central nervous system drugs } \\
\hline Opioids & $500(5.4)$ & $194(6.9)$ \\
\hline Hypnotic and sedatives & $898(9.7)$ & $286(10.1)$ \\
\hline Anxiolytics & 945 (10.2) & $272(9.6)$ \\
\hline Antidepressants (SSRI) & $434(4.7)$ & $149(5.3)$ \\
\hline Antipsychotics & $140(1.5)$ & $34(1.2)$ \\
\hline Antiparkinson drugs & $61(0.6)$ & $18(0.9)$ \\
\hline Anticholinergics & $335(3.6)$ & $124(4.4)$ \\
\hline Antihistaminics & $480(5.2)$ & $158(5.6)$ \\
\hline \multicolumn{3}{|l|}{ Drugs affecting cerebrovascular and cardiovascular disease } \\
\hline Nitrates & $545(5.9)$ & $193(6.8)$ \\
\hline Vitamin $\mathrm{K}$ antagonists & $803(7.9)$ & $255(9.0)$ \\
\hline Lipid lowering drugs & $2450(26.6)$ & $805(28.5)$ \\
\hline Antiplatelets & $2180(23.6)$ & $727(25.7)$ \\
\hline Diuretics & $1981(21.5)$ & $666(23.6)$ \\
\hline$\beta$-blockers & 2015 (21.8) & $637(22.5)$ \\
\hline $\mathrm{CCB}$ & $1219(13.2)$ & $396(14.0)$ \\
\hline ACE inhibitors & $2686(29.1)$ & $881(31.2)$ \\
\hline Anti-arrhythmic drugs & $147(1.6)$ & $41(1.5)$ \\
\hline \multicolumn{3}{|l|}{ Other drugs } \\
\hline Corticosteroids & $932(10.1)$ & $435(15.4)$ \\
\hline Antibiotics & $1914(20.7)$ & 703 (24.9) \\
\hline NSAIDs & $734(8.7)$ & $223(7.9)$ \\
\hline \multicolumn{3}{|l|}{ Respiratory drugs } \\
\hline Mucolytics & $447(4.8)$ & $173(6.1)$ \\
\hline LTRA & 180 (1.9) & $69(2.4)$ \\
\hline SAAC (Ipratropium) & $579(6.3)$ & $320(11.3)$ \\
\hline SABA & 1597 (17.3) & $600(21.2)$ \\
\hline LABA & 3556 (38.5) & 1066 (37.7) \\
\hline ICS & 3925 (42.5) & 1174 (41.5) \\
\hline Xanthines & $101(1.1)$ & $34(1.2)$ \\
\hline
\end{tabular}

Data are presented as $\mathrm{n}(\%)$ or mean + SD, unless otherwise stated. COPD: chronic obstructive pulmonary disease; GP: general practitioner; TIA: transient ischaemic attack; SSRI: selective serotonin reuptake inhibitor; CCB: calcium channel blockers; ACE: angiotensin-converting enzyme; NSAID: non-steroidal anti-inflammatory drug; LTRA: leukotriene receptor antagonist; SAAC: shortacting anticholinergics; SABA: short-acting $\beta$-agonists; LABA: long-acting $\beta$-agonists; ICS: inhaled corticosteroids. Bold values are statistically significant different between tiotropium Respimat SMI against tiotropium HandiHaler. 
TABLE 2 Patient characteristics at start of treatment episodes during follow-up

\begin{tabular}{|c|c|c|}
\hline Characteristics & Tiotropium HandiHaler & Tiotropium Respimat \\
\hline Number of patients $n$ & 19341 & 5181 \\
\hline $\begin{array}{l}\text { Age years } \\
\text { Sex }\end{array}$ & $68.49 \pm 11.53$ & $68.14 \pm 11.84$ \\
\hline Male & $9955(51.5)$ & $2727(52.6)$ \\
\hline Female & $9386(48.5)$ & $2454(47.4)$ \\
\hline Smoking history & $15053(77.8)$ & $4024(77.7)$ \\
\hline COPD diagnosis & $17909(92.6)$ & 4755 (91.8) \\
\hline COPD duration years & $5.53(5.00)$ & $5.96(4.84)$ \\
\hline \multicolumn{3}{|l|}{ COPD severity $n$} \\
\hline Antibiotics in 1 year prior & $0.48 \pm 1.1$ & $0.67 \pm 1.2$ \\
\hline Systemic corticosteroids in 1 year prior & $0.64 \pm 1.6$ & $1.06 \pm 2.9$ \\
\hline GP visits in the 1 year prior & $8.07 \pm 6.7$ & $9.60 \pm 7.7$ \\
\hline Hospitalisation for COPD exacerbation in 1 year prior & $476 \pm 2.5$ & $231 \pm 4.5$ \\
\hline Consultation with respiratory physician in 1 year prior & $6145 \pm 31.8$ & $2479 \pm 47.8$ \\
\hline \multicolumn{3}{|l|}{ Comorbidity (medical history of any of the conditions) } \\
\hline Asthma & $6091(31.5)$ & $1653(31.9)$ \\
\hline Angina pectoris & $2716(14.0)$ & $787(15.2)$ \\
\hline Ischaemic heart disease & $1632(8.4)$ & $473(9.1)$ \\
\hline Peripheral arterial disease & $2752(14.2)$ & $807(15.6)$ \\
\hline Myocardial infarction & $1413(7.3)$ & $471(9.1)$ \\
\hline Stroke or TIA & $1618(8.4)$ & $537(10.4)$ \\
\hline Heart failure & $2062(10.7)$ & $693(13.3)$ \\
\hline Arrhythmia & $1831(9.5)$ & $567(10.9)$ \\
\hline Hypertension & $7799(40.3)$ & $2153(41.6)$ \\
\hline Dyslipidaemia (lipid disorders) & $3268(16.9)$ & $1080(20.8)$ \\
\hline Cancer & $3142(16.2)$ & $914(17.6)$ \\
\hline Pneumonia ( 1 year before) & $1177(6.1)$ & $458(8.8)$ \\
\hline Parkinsonism & $169(0.9)$ & $43(0.8)$ \\
\hline Depression & $2619(13.5)$ & $748(14.4)$ \\
\hline Dementia & $379(1.9)$ & $95(1.8)$ \\
\hline Diabetes mellitus & $3585(18.5)$ & $1040(20.1)$ \\
\hline Renal failure & $1650(8.5)$ & $518(10.0)$ \\
\hline \multicolumn{3}{|l|}{ Use of concomitant medication at start of prescription } \\
\hline \multicolumn{3}{|l|}{ Central nervous system drugs } \\
\hline Opioids & $1131(5.8)$ & $364(7.0)$ \\
\hline Hypnotic and sedatives & $1916(9.9)$ & $535(10.3)$ \\
\hline Anxiolytics & $1995(10.3)$ & $508(9.8)$ \\
\hline Antidepressants (SSRI) & $918(4.7)$ & $274(5.3)$ \\
\hline Antipsychotics & $314(1.6)$ & $62(1.2)$ \\
\hline Antiparkinson drugs & $132(0.7)$ & $40(0.8)$ \\
\hline Anticholinergics & $771(4.0)$ & $234(4.5)$ \\
\hline Antihistaminics & $1018(5.3)$ & $285(5.5)$ \\
\hline \multicolumn{3}{|l|}{ Drugs affecting cerebrovascular and cardiovascular disease } \\
\hline Nitrates & $1137(5.9)$ & $383(7.4)$ \\
\hline Vitamin $\mathrm{K}$ antagonists & $1723(8.9)$ & $465(9.0)$ \\
\hline Lipid lowering drugs & 5095 (26.3) & $1509(29.1)$ \\
\hline Antiplatelets & $4519(23.4)$ & 1394 (26.9) \\
\hline Diuretics & $4006(20.7)$ & $1209(23.3)$ \\
\hline$\beta$-blockers & $4189(21.7)$ & 1199 (23.1) \\
\hline CCB & 2494 (12.9) & $739(14.3)$ \\
\hline ACE inhibitors & 5591 (28.9) & $1602(30.9)$ \\
\hline Anti-arrhythmic drugs & $312(1.6)$ & $104(2.0)$ \\
\hline \multicolumn{3}{|l|}{ Other drugs } \\
\hline Corticosteroids & $1839(9.5)$ & $728(14.1)$ \\
\hline Antibiotics & $3663(18.9)$ & 1135 (21.9) \\
\hline NSAIDs & $1495(7.7)$ & $386(7.5)$ \\
\hline \multicolumn{3}{|l|}{ Respiratory drugs } \\
\hline Mucolytics & $903(4.7)$ & $304(5.9)$ \\
\hline LTRA & $376(4.7)$ & $126(2.4)$ \\
\hline SAAC (Ipratropium) & $997(5.2)$ & $481(9.3)$ \\
\hline SABA & $3231(16.7)$ & $1092(21.1)$ \\
\hline LABA & 7333 (37.9) & 1653 (37.9) \\
\hline ICS & 7961 (41.2) & $2137(41.2)$ \\
\hline Xanthines & $196(1.0)$ & $67(1.3)$ \\
\hline
\end{tabular}

Data are presented as $\mathrm{n}(\%)$ or mean $\pm \mathrm{SD}$, unless otherwise stated. COPD: chronic obstructive pulmonary disease; GP: general practitioner; TIA: transient ischaemic attack; SSRI: selective serotonin reuptake inhibitor; CCB: calcium channel blockers; ACE: angiotensin-converting enzyme; NSAID: non-steroidal anti-inflammatory drug; LTRA: leukotriene receptor antagonist; SAAC: shortacting anticholinergics; SABA: short-acting $\beta$-agonists; LABA: long-acting $\beta$-agonists; ICS: inhaled corticosteroids. Bold values are statistically significant different between tiotropium Respimat SMI against tiotropium HandiHaler. 
TABLE 3 Crude and adjusted hazard ratios (HRs) for all-cause mortality in users of tiotropium Respimat versus users of tiotropium HandiHaler

\begin{tabular}{|c|c|c|c|}
\hline & Tiotropium Respimat & $\begin{array}{l}\text { Tiotropium } \\
\text { Respimat } 2.5 \mu \mathrm{g}\end{array}$ & $\begin{array}{l}\text { Tiotropium } \\
\text { Respimat } 5 \mu \mathrm{g}\end{array}$ \\
\hline $\begin{array}{l}\text { Deaths } n \\
\text { Unadjusted HR (crude) }\end{array}$ & $\begin{array}{c}124 \\
1.57(1.28-1.92)\end{array}$ & $\begin{array}{c}27 \\
1.67(1.13-2.47)\end{array}$ & $\begin{array}{c}97 \\
1.54(1.23-1.93)\end{array}$ \\
\hline \multicolumn{4}{|l|}{ Covariates included in the Cox model to calculate adjusted HRs } \\
\hline Age & $1.61(1.31-1.98)$ & $1.54(1.04-2.29)$ & $1.63(1.30-2.03)$ \\
\hline$+\operatorname{sex}$ & $1.60(1.30-1.96)$ & $1.57(1.06-2.32)$ & $1.60(1.28-2.01)$ \\
\hline+ number of GP visits in 1 year prior to episode start & $1.36(1.11-1.68)$ & $1.31(0.88-1.94)$ & $1.39(1.10-1.75)$ \\
\hline + hospitalisation for COPD in 1 year prior to episode start & $1.34(1.09-1.66)$ & $1.26(0.85-1.87)$ & $1.37(1.09-1.72)$ \\
\hline $\begin{array}{l}\text { + number of prescriptions of antibiotics for treatment of LRTI in } \\
1 \text { year prior to episode start }\end{array}$ & $1.34(1.09-1.65)$ & $1.24(0.83-1.84)$ & $1.37(1.09-1.73)$ \\
\hline $\begin{array}{l}+ \text { consultation with respiratory physician in } 1 \text { year prior to episode } \\
\text { start }\end{array}$ & $1.26(1.02-1.57)$ & $1.22(0.82-1.82)$ & $1.28(1.02-1.62)$ \\
\hline+ duration of COPD & $1.27(1.03-1.58)$ & $1.20(0.82-1.79)$ & $1.28(1.02-1.62)$ \\
\hline
\end{tabular}

Data are presented as HR (95\% CI), unless otherwise stated. GP: general practitioner; COPD: chronic obstructive pulmonary disease; LRTI: lower respiratory tract infection. " : variables that changed the crude HR with more than $5 \%$. Bold indicates statistical significance.

The association between the use of tiotropium Respimat and risk of death was the highest for cardio- and cerebrovascular death as cause (adjusted HR 1.56, 95\% CI 1.08-2.25), followed by respiratory death (adjusted HR 1.34, 95\% CI 0.80-2.22) (table 4), although the 95\% CI were wide and overlapping.

When repeating the analysis, excluding patients who died of both a cardiovascular and respiratory cause of death $(n=29)$, the association remained (adjusted HR 1.60, 95\% CI 1.06-2.40) (data not shown).

\section{Sensitivity analyses}

The risk was higher in patients with co-existing cardiovascular disease (adjusted HR 1.36, 95\% CI 1.071.73) than in patients without (adjusted HR 1.02, 95\% CI 0.61-1.71) (table 5). Exclusion of episodes in which the formulation of tiotropium was changed did not alter the association between use of Respimat and death (adjusted HR 1.23, 95\% CI 0.98-1.55). Further sensitivity analyses showed little impact of other assumptions but lost statistical significance due to low numbers. The associations remained when a) excluding prevalent users, b) not considering a 30-day carry over effect, or c) extending treatment episodes up to the next episode (table 5). The association was the lowest when considering only the first episode of drug use (adjusted HR 1.17, 95\% CI 0.85-1.60). Finally, the association between use of Respimat and death remained upon propensity score adjustment (adjusted HR 1.32, 95\% CI 1.05-1.67).

\section{Discussion}

In this observational cohort study in the general Dutch population of patients aged $\geqslant=40$ years, we found an almost $30 \%$ increased risk of death in patients using tiotropium Respimat SMI compared with tiotropium HandiHaler. Cause-specific analysis showed that the risk was highest for cardiovascular death.

Importantly, the risk of death in patients using tiotropium Respimat SMI was higher in patients with coexisting cardiovascular disease than in patients without. Since COPD is associated with multiple comorbidities, including cardiovascular disease, and since COPD patients with cardiovascular disease are often excluded from randomised controlled trials, our observational cohort study provides novel and important data concerning the safety of tiotropium Respimat SMI.

So far, few data are available on the head-to-head comparison between tiotropium HandiHaler and Respimat SMI. In a pooled analysis of two 30-week, double-blind double-dummy, crossover studies, 207 patients were randomised to receive once-daily tiotropium Respimat SMI, tiotropium HandiHaler or placebo [12]. Although this study showed non-inferiority of tiotropium Respimat SMI in comparison with tiotropium HandiHaler in terms of improvement of lung function (forced expiratory volume in $1 \mathrm{~s}$ ) and no significant differences in terms of mortality, there was a significantly higher systemic exposure in patients 
TABLE 4 Crude and adjusted hazard ratios (HRs) for cause-specific mortality in users of tiotropium Respimat versus users of tiotropium HandiHaler

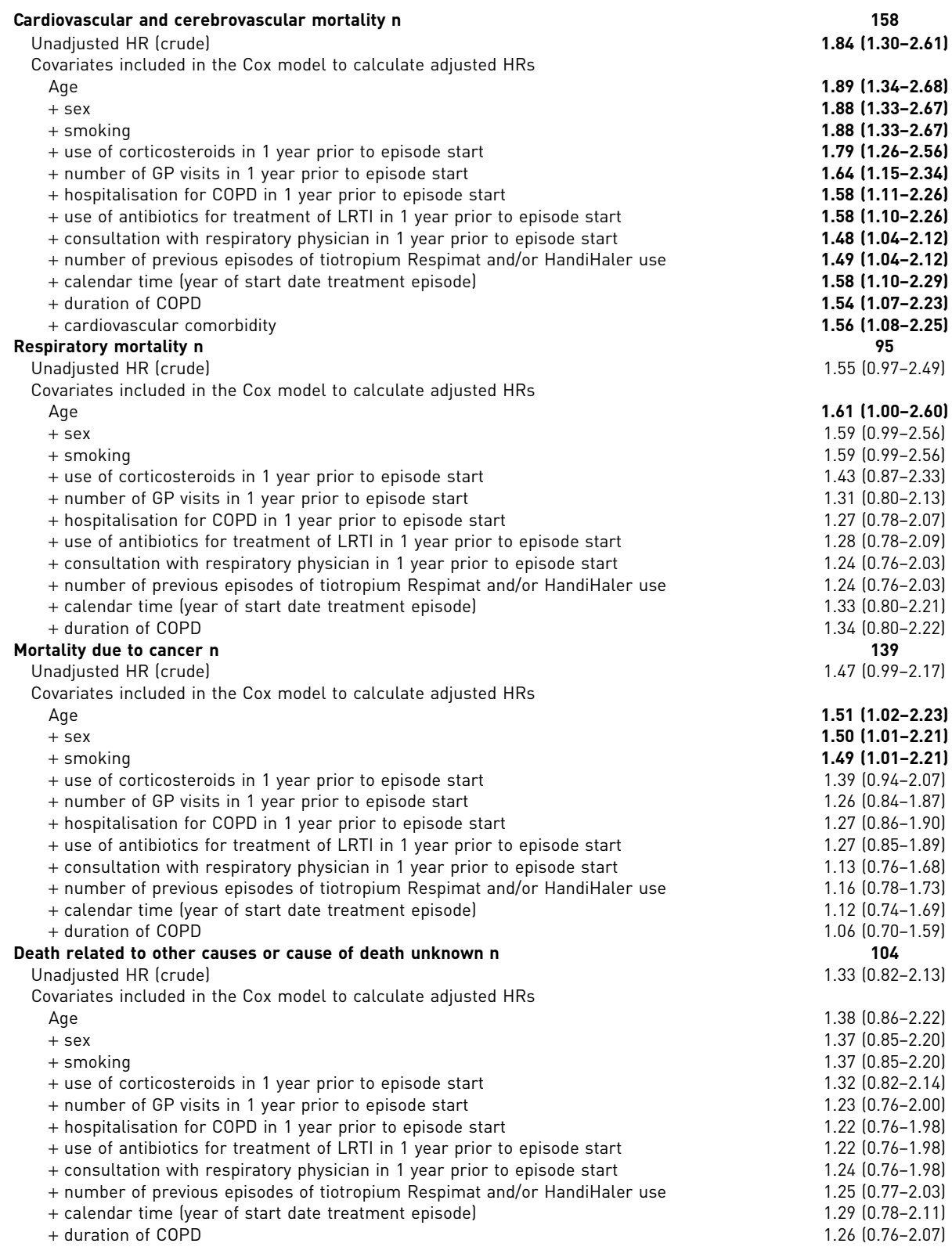

Data are presented as HR ( $95 \%$ CI), unless otherwise stated. GP: general practitioner; COPD: chronic obstructive pulmonary disease; LRTI: lower respiratory tract infection. Bold indicates statistical significance.

treated with tiotropium Respimat SMI $10 \mu \mathrm{g}$ daily. A more recent study in Japanese COPD patients, but with shorter duration of follow-up, compared the safety and efficacy of tiotropium $5 \mu \mathrm{g}$ via Respimat SMI to $18 \mu \mathrm{g}$ tiotropium HandiHaler and did not observe a difference in safety and efficacy of both formulations [29].

To our knowledge, our study is the first to compare the safety of the two devices of tiotropium on a large scale during a long period of follow-up. We did observe a small increased risk of dying in patients treated with tiotropium Respimat SMI. It is unclear whether this is a true association or whether this association could be explained by residual confounding. It is believed that the improved delivery of the tiotropium Respimat results in higher plasma concentrations of tiotropium increasing the risk of anticholinergic cardiovascular effects (arrhythmia) [18]. We mainly observed an increased risk for cardiovascular and cerebrovascular death, and in patients with underlying cardiovascular disease which is in favour of this 
TABLE 5 Sensitivity analyses: crude and adjusted hazard ratios (HRs) for all-cause mortality in users of tiotropium Respimat versus users of tiotropium HandiHaler

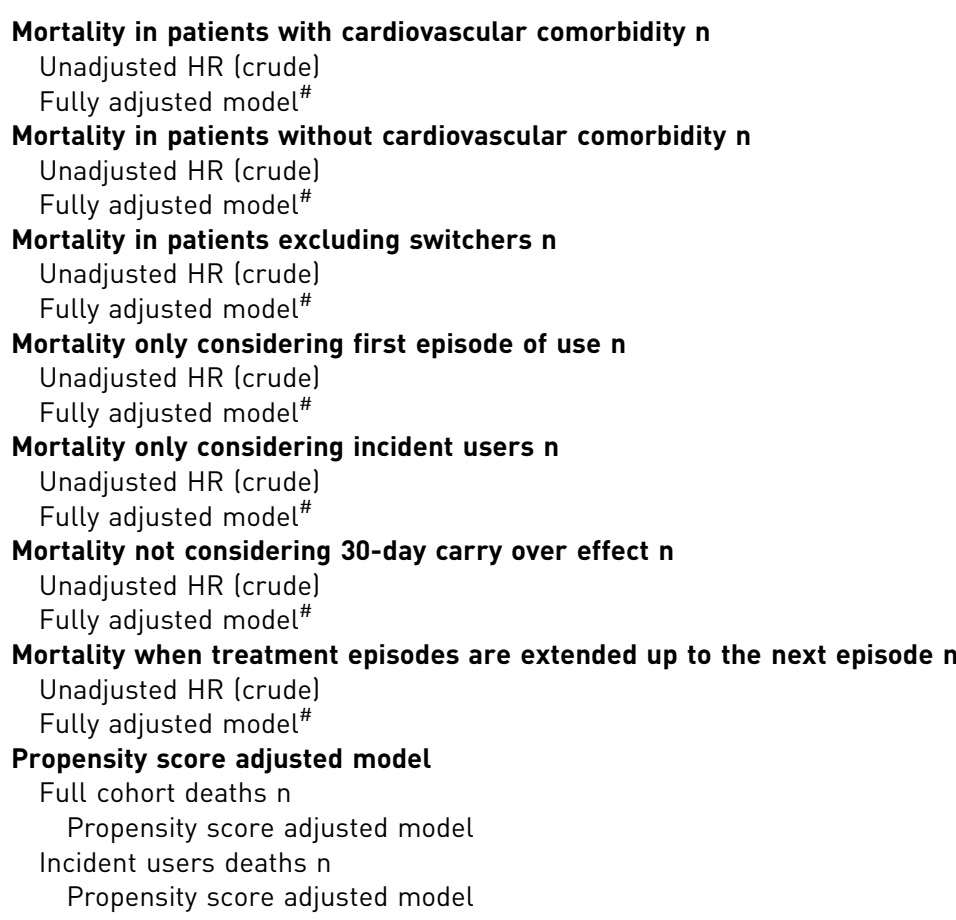

$1.62(1.29-2.04)$

$1.36(1.07-1.73)$ 109

$1.25(0.77-2.02)$

$1.02(0.61-1.71)$ 472

$1.49(1.20-1.86)$

$1.23(0.98-1.55)$ 258

$1.39(1.03-1.88)$

$1.17(0.85-1.60)$ 165

$1.59(1.17-2.16)$

$1.27(0.93-1.75)$

$1.51(1.19-1.91)$

$1.21(0.94-1.56)$ 388

$1.53(1.21-1.94)$

$1.22(0.95-1.57)$

496

$1.32(1.05-1.67)$

165

$1.29(0.90-1.84)$

Data are presented as HR (95\% CI), unless otherwise stated. " : adjusted for age, sex, smoking, use of systemic corticosteroids in 1 year prior to episode start, number of general practitioner visits in 1 year prior to episode start, hospitalisation for chronic obstruction pulmonary disease (COPD) exacerbation, use of antibiotics for treatment of lower respiratory tract infection in 1 year prior to episode start, consultation with respiratory physician in one year prior to episode start, previous episodes of tiotropium use, calendar time and duration of COPD. Bold indicates significance.

hypothesis; however, we did not identify an obvious dose-response relationship, although it should be noted that tiotropium Respimat SMI in the Netherlands is registered for $5 \mu$ g once daily and doses above are considered off-label.

As for all observational studies, our study has strengths but also limitations. The main strength of this study is the study design, its large cohort size and the detailed information that is available on underlying comorbidity. In addition, as we used data from a primary care database, where patient data is prospectively collected in view of patient care and irrespective of any research question, selection bias is unlikely. Moreover, the source population being used is representative of the general population, and thereby facilitates generalisability of our results.

Being observational, the study is sensitive to bias and confounding. Indeed, when looking at the baseline characteristics of patients treated with tiotropium Respimat SMI versus tiotropium HandiHaler, it was noticed that patients treated with tiotropium Respimat SMI had more severe COPD, more often consulted a respiratory physician and had more underlying (cardiovascular) comorbidity. As these factors could be important confounders in the association between the use of Respimat SMI and mortality, it was thus important to conduct adjusted analyses. To adjust for COPD severity, we used an algorithm already successfully used by other research groups [24-26]. To control for confounding by indication, we conducted a sensitivity analysis in which we adjusted for the propensity scores for the likelihood of being prescribed tiotropium Respimat SMI and the association remained. Despite these measures, remaining confounding, including confounding of COPD severity might still be an issue. Ideally, COPD severity should be assessed by pulmonary function, preferably post-bronchodilation. In primary care however, pulmonary function is not routinely assessed and not systematically recorded in the database. Finally, due to the nature of the database, exposure was based on prescription data rather than on actual drug intake.

Boehringer Ingelheim is currently conducting the TIOSPIR trial, a large international safety study to elucidate the risk of mortality in patients treated with tiotropium Respimat SMI, using tiotropium HandiHaler as reference category. This study enrolled up to 17000 patients who are followed up over 2 years and results of the trial are expected in 2014 [30]. In addition, as the TIOSPIR trial excluded patients 
with a recent history of myocardial infarction, unstable or life-threatening cardiac arrhythmia or patients hospitalised for cardiac failure (New York Heart Association class III or IV) during the past year, our data should be considered as added value as we did not exclude these patients. We recommend that, until further data become available, physicians should be aware that COPD patients with arrhythmia or a history of cardiovascular disease might be particularly at risk.

\section{References}

1 World Health Organization (WHO). The world health report 2008 - primary health care (now more than ever). 2008. www.who.int/whr/2008/08_chap1_en.pdf Date last accessed: June 27, 2013.

Global Strategy for Diagnosis, Management, and Prevention of COPD. 2011.

3 Barr RG, Bourbeau J, Camargo CA, et al. Tiotropium for stable chronic obstructive pulmonary disease: a metaanalysis. Thorax 2006; 61: 854-862.

4 Tashkin D, Kesten S. Long-term treatment benefits with tiotropium in COPD patients with and without short-term bronchodilator responses. Chest 2003; 123: 1441-1449.

5 Niewoehner DE, Rice K, Cote C, et al. Prevention of exacerbations of chronic obstructive pulmonary disease with tiotropium, a once-daily inhaled anticholinergic bronchodilator: a randomized trial. Ann Intern Med 2005; 143: 317-326.

6 Tashkin DP, Celli B, Senn S, et al. A 4-year trial of tiotropium in chronic obstructive pulmonary disease. $N$ Engl J Med 2008; 359: 1543-1554.

7 Casaburi R, Mahler DA, Jones PW, et al. A long-term evaluation of once-daily inhaled tiotropium in chronic obstructive pulmonary disease. Eur Respir J 2002; 19: 217-224.

8 Vincken W, van Noord JA, Greefhorst AP, et al. Improved health outcomes in patients with COPD during one year's treatment with toptropium. Eur Resp J 2002; 19: 209-216.

9 Donohue JF, van Noord JA, Bateman ED, et al. A 6-month, placebo-controlled study comparing lung function and health status changes in COPD patients treated with tiotropium or salmeterol. Chest 2002; 122: 47-55.

10 Brusasco V, Hodder R, Miravitlles M, et al. Health outcomes following treatment for six months with once daily tiotropium compared with twice daily salmeterol in patients with COPD. Thorax 2003; 58: 399-404.

11 Okudan N, Gok M, Gokbel H, et al. Single dose of tiotropium improves the 6-minute walk distance in chronic obstructive pulmonary disease. Lung 2006; 184: 201-204.

12 van Noord JA, Cornelissen PJ, Aumann JL, et al. The efficacy of tiotropium administered via Respimat Soft Mist Inhaler or HandiHaler in COPD patients. Respir Med 2009; 103: 22-29.

13 Pitcairn G, Reader S, Pavia D, et al. Deposition of corticosteroid aerosol in the human lung by Respimat Soft Mist inhaler compared to deposition by metered dose inhaler or by Turbuhaler dry powder inhaler. J Aerosol Med 2005; 18: 264-272.

14 Caillaud D, Le Merre C, Martinat Y, et al. A dose-ranging study of tiotropium delivered via Respimat Soft Mist Inhaler or HandiHaler in COPD patients. Int J Chronic Obstruct Pulmon Dis 2007; 2: 559-565.

15 Lee TA, Pickard AS, Au DH, et al. Risk for death associated with medications for recently diagnosed chronic obstructive pulmonary disease. Ann Intern Med 2008; 149: 380-390.

16 Singh S, Loke YK, Furberg CD. Inhaled anticholinergics and risk of major adverse cardiovascular events in patients with chronic obstructive pulmonary disease: a systematic review and meta-analysis. Jama 2008; 300: 1439-1450.

17 Michele TM, Pinheiro S, Iyasu S. The safety of tiotropium-the FDA's conclusions. N Engl J Med 2010; 363: 1097-1099.

18 Singh S, Loke YK, Enright PL, et al. Mortality associated with tiotropium mist inhaler in patients with chronic obstructive pulmonary disease: systematic review and meta-analysis of randomised controlled trials. BMJ 2011; 342 : d3215.

19 Dong YH, Lin HH, Shau WY, et al. Comparative safety of inhaled medications in patients with chronic obstructive pulmonary disease; systematic review and mixed treatment comparison meta-analysis of randomised controlled trials. Thorax 2013; 68: 48-56.

20 van der Lei J, Duisterhout JS, Westerhof HP, et al. The introduction of computer-based patient records in The Netherlands. Ann Intern Med 1993; 119: 1036-1041.

21 Lamberts H, Wood M, Hofmans-Okkes IM. International primary care classifications: the effect of fifteen years of evolution. Fam Pract 1992; 9: 330-339.

22 Vlug AE, van der Lei J, Mosseveld BM, et al. Postmarketing surveillance based on electronic patient records: the IPCI project. Methods Inf Med 1999; 38: 339-344.

23 Epstein M. Guidelines for good pharmacoepidemiology practices (GPP). Pharmacoepidemiol Drug Saf 2005; 14: 589-595.

24 Curkendall SM, Lanes S, de Luise C, et al. Chronic obstructive pulmonary disease severity and cardiovascular outcomes. Eur J Epidemiol 2006; 21: 803-813.

25 Eisner MD, Trupin L, Katz PP, et al. Development and validation of a survey-based COPD severity score. Chest 2005; 127: 1890-1897.

26 Soriano JB, Maier WC, Visick G, et al. Validation of general practitioner-diagnosed COPD in the UK General Practice Research Database. Eur J Epidemiol 2001; 17: 1075-1080.

27 de Vries F, Setakis E, Zhang B, et al. Long-acting $\beta 2$-agonists in adult asthma and the pattern of risk of death and severe asthma outcomes: a study using the GPRD. Eur Respir J 2010; 36: 494-502.

28 Huybrechts KF, Gerhard T, Crystal S, et al. Differential risk of death in older residents in nursing homes prescribed specific antipsychotic drugs: population based cohort study. BMJ 2012; 344: e977.

29 Ichinose M, Fujimoto T, Fukuchi Y. Tiotropium 5microg via Respimat and 18microg via HandiHaler; efficacy and safety in Japanese COPD patients. Respir Med, 104: 228-236.

30 ClinicalTrials.gov. NCT 01126437 Comparison of tiotropium in the Handihaler versus the Respimat in COPD. 2012. 